European Journal of

Health Sciences

(EJHS)
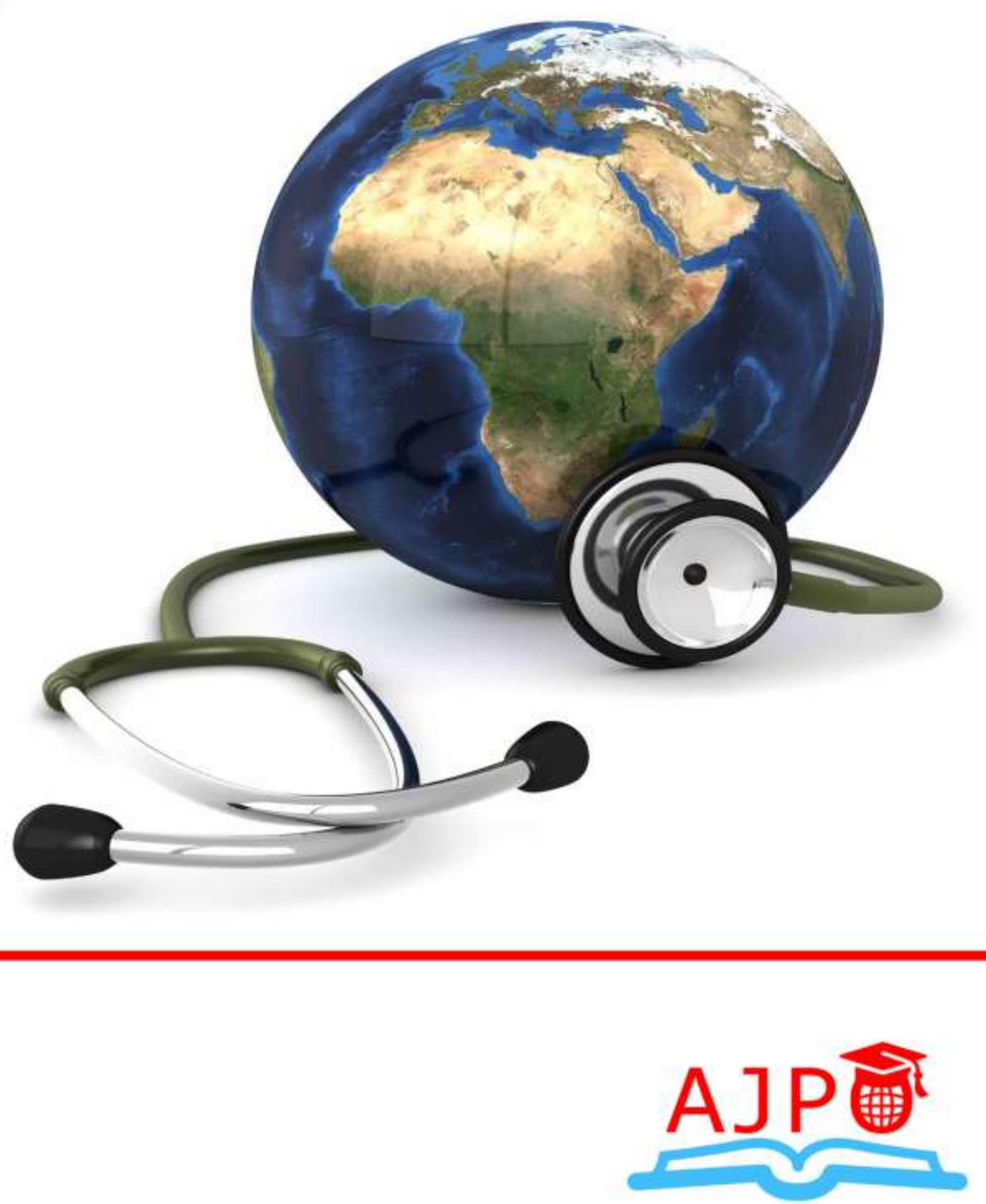


\title{
PRECONCEPTION KNOWLEDGE AND PRACTICES AMONG WOMEN IN FERTILITY AGE IN THE TAMALE TEACHING HOSPITAL OF GHANA
}

\author{
1*Obed Kwaku Duah Asumadu (BSc. Nursing) \\ Department of Nursing, School of Allied Health Sciences \\ University for Development Studies, Tamale, Ghana \\ *Email: asumaduobed@yahoo.com \\ ${ }^{2}$ Sandra Esi Effrim (BSc. Midwifery) \\ Department of Midwifery, School of Allied Health Sciences \\ University for Development Studies, Tamale, Ghana \\ ${ }^{3}$ Beatrice Ennin (BSc. Midwifery) \\ Department of Midwifery, School of Allied Health Sciences \\ University for Development Studies, Tamale, Ghana \\ ${ }^{4}$ Angela Owusuah Amoabeng (BSc. Midwifery) \\ Department of Midwifery, School of Allied Health Sciences \\ University for Development Studies, Tamale, Ghana \\ ${ }^{5}$ Rosina Darcha (MPhil, RM) \\ Department of Midwifery, School of Allied Health Sciences \\ University for Development Studies, Tamale, Ghana
}

${ }^{6}$ Akwasi Boakye-Yiadom (MSc, B.Ed)

Department of Public Health, School of Allied Health Sciences

University for Development Studies, Tamale, Ghana

${ }^{7}$ Wisdom Peprah (BSc. Community Nutrition)

Department of Nutritional Sciences, School of Allied Health Sciences

University for Development Studies, Tamale, Ghana

${ }^{8}$ Joel Afram Saah (B.Ed Health Science)

Department of Public Health, School of Allied Health Sciences

University for Development Studies, Tamale, Ghana

${ }^{9}$ Richard Opoku Asare (MPhil, B.Ed, RN (Dip)-RMN, Cert.Ed)

College of Nursing, Ntotroso

Ahafo Region, Ghana 


\begin{abstract}
Purpose: The aim of this study was to assess preconception knowledge and practices and its effect on birth outcomes among puerperal women in the Tamale Teaching Hospital.

Methodology: The study employed analytic cross-sectional study design with a quantitative approach. A semi-structured questionnaire was used where questions on knowledge of preconception were adopted from Southampton Women's Survey, 2006. Puerperal women in the postnatal unit of the Tamale Teaching Hospital, who were yet to be discharged, including referred cases, were selected as target population for this study. The exclusion criteria were women who have never delivered and menopausal women. The sample size was 363 puerperal women. Purposive sampling method was used to attain the required sample. Data was analyzed using SPSS version 25 . In the analyses, a p-value $<0.05$ was considered statistically significant when variables were cross-tabulated.

Findings: The results of the study revealed a high proportion of puerperal women $161(44.3 \%)$ were above 30 years. The mean age was $30.56 \pm 6.44$ years. The study found that $37.2 \%$ women had knowledge on preconception care. There was a significant association between folic acid intake and postpartum haemorrhage $(r=-0.183, \mathrm{p}<0.0001)$. There was no statistical association between birth outcomes and concurrent loss of pregnancy and number of pregnancies lost except for birth weight $(r=0.202, \mathrm{p}=0.000)$. Albeit preconception care knowledge was low among puerperal women, it significantly influenced postpartum haemorrhage and pregnancy induced hypertension but not antepartum hemorrhage and birth weight.

Recommendation: At the community level the study recommended to the Ghana Health Service that a mother-to-mother support group be formed among women in their reproductive age and this could help encourage one another to discuss about their health before pregnancy and share success stories on birth outcomes and report to the facility in case of any problems.
\end{abstract}

Key words: Preconception, Knowledge, Practices, Tamale Teaching Hospital 


\section{INTRODUCTION}

The expansion of access to preconception knowledge and counseling among women in fertility age is proposed as a strategy for achieving progressive women's health as captured in the third Sustainable Development Goal (Chuang, Velott, \& Weisman, 2010). Preconception care involves provision of biomedical, behavioral and social health interventions to women and couples before conception occurs, aimed at improving their health status, reducing behaviours and individual and environmental factors that could contribute to poor maternal and child health outcomes (Al-Akour, Sou'Ub, Mohammad, \& Zayed, 2015; Harelick, Viola, \& Tahara, 2011).

Maternal, newborn and child health $(\mathrm{MNCH})$ care approach is important during the preconception period since the health and well-being of women, newborns and children are closely linked and ought to be managed in a unified manner (Kinney et al., 2010). The achievement of $\mathrm{MNCH}$ include interventions directed at improving nutritional status through balanced energy-protein supply, folic acid supplementation/fortification, micronutrient supplementation among others and maintaining healthy lifestyle (Frey \& Files, 2006; Gunaratna et al., 2015; Lassi, Dean, Mallick, \& Bhutta, 2014).

Preconception care includes a set of interventions that aims to identify and modify biomedical, behavioural and social risks to women's health or pregnancy outcome through prevention and management (Seshadri, Nelson-Piercy, \& Chappell, 2012). This statement was affirmed by the World Health Organization (WHO) which added that the ultimate aim of preconception care is to improve maternal and child health, in both the short and long term (WHO, 2013). It is, therefore, an essential and vital practice, as it lays the foundation for future health of the mother, her child and her family (Mitchell, Levis, \& Prue, 2012). Besides, it is an ongoing component of healthcare services that must be provided for both men and women in their reproductive age to ensure that they are healthy (WHO, 2013). In view of this the act of embracing preconception care serves as a golden opportunity that can identify health risk factors in pregnancy and enable healthcare givers to conduct any required interventions earlier before pregnancy occurs to prevent harmful exposures from affecting the developing foetus (Dandekar \& Hessler, 2014; Kinney et al., 2010; Mittal et al., 2016).

These interventions include birth spacing and prevention of teenage pregnancy as young mothers often are not physically mature enough to deliver a baby, leaving them and their children at risk for death or disability from obstructed labor, fistulas, premature birth, or low birth weight. At the same time, early childbearing negatively affects educational and economic opportunities; women with lower educational attainment have greater risks of adverse pregnancy outcomes, are less knowledgeable about health-prevention activities, and family planning. Their children have fewer options for education, optimal growth and development and have a higher risk of mortality (Lassi et al., 2014). Seshadri et al. (2012) were right when their study concluded that preconception care was interventions characterized by the need to start and sometimes complete a designated intervention before conception occurs.

Preconception care knowledge and practices could have multiple positive impacts on birth outcomes as its ultimate aim is to improve maternal and child health, in both the short and long term. This was to reiterate the World Health Organization's assertion that there is widespread consensus that to reduce maternal and childhood mortality, a continuum of care needs to be 
provided through pregnancy, childbirth, the postnatal period (addressing both mothers and infants), infancy, childhood, adolescence and adulthood. There is also widespread agreement that actions are needed at the community, primary care and referral care level to deliver this continuum of care (WHO, 2013).

Preconception knowledge of women is focused on women's ability to identify medical and social conditions that may put the mother or fetus at risk. Therefore, the notion of preconception knowledge among women aims to provide understanding to the existing risks before pregnancy, whereby resources may be used to improve reproductive health of women, men and couples in order to optimize health and knowledge before conceiving a pregnancy (Ojukwu, Patel, Stephenson, Howden \& Shawe, 2016).

Counseling administered to influence knowledge and attitudes about preconception and its effects on a potential pregnancy is shown to manifest large impact (Mittal, Dandekar, \& Hessler, 2014). It is therefore important to note that a reproductive life plan is a brief, cost effective preconception and contraception counseling tool in the primary care setting for women. This means that increasing knowledge about reproductive health is incomplete when preconception knowledge is not present. In view of this lack of knowledge about common preconception risk factors seems to be one of the critical factors hindering the widespread application of the practice.

In a population study in Rotterdam, half of the non-pregnant study population $(n=631)$ were unaware of the adverse effect of smoking and being overweight on fertility. Although, this outcome is in contrast with other results, specific preconception health knowledge, e.g., folic acid use, was also scarce ( $\mathrm{p}<0.001)$ (Gunaratna et al., 2015). Notwithstanding, several studies have shown that there is positive correlation between women's preconception care knowledge and effective reproductive health outcomes (Singh et al., 2010).

In terms of preconception practices, Stephenson and colleagues (2014) reported that despite the high level of pregnancy planning in their survey of not less than 1000 sample size in three North London hospitals, and previous miscarriage, stillbirth or termination for fetal abnormalities, 34\% of all women reported acquiring no information about preconception health behaviours and $49 \%$ reported no practice of preconception care knowledge. Just over half (51\%) of all women, and fewer than two thirds (63\%) of women with planned pregnancies, took folic acid before pregnancy.

Since maternal assessment before pregnancy encompasses family history, obstetric history and general physical examination of the potential mother; family history of chronic disorders, firstdegree consanguineous (relationship by descent) marriages and planning pregnancy has been shown to be associated with awareness of preconception care. It was reported by Al-Akour and colleagues (2015) in their study on awareness of preconception care among women and men from Jordan that close to $50 \%$ of participants were aware of the serious impact that a woman's and man's family history can have on the health of their babies. They concluded that a significant number of their respondents recommended changes be made prior to conception.

Though the world has made significant improvement in saving the lives of mothers and children since the adoption and implementation of major programmes such as the Millennium Development Goals 4 and 5 in 2000 (Gunaratna et al., 2015), there were still 287,000 maternal 
and 2.9 million newborn deaths each year, with an additional 2.6 million stillbirths worldwide (UNICEF, 2010). However, data from the Tamale Teaching Hospital (TTH) showed that the dynamics of specific maternal and neonatal health outcomes are not pointing in the right direction. For instance, the prevalence of still birth decreased slightly from 313 to 251 between 2015 and 2016, it later hiked to 342 in 2017 and further increased to 379 in 2018; low birth weight increased from 1516 to 1708 between 2015 and 2016 but reduced from 2098 to 1602 from 2017 to 2018. Antepartum hemorrhage (APH), postpartum hemorrhage (PPH) and pregnancy induced hypertension (PIH) was also rife in 2015 where 58,101 and 257 was recorded respectively. Despite data on APH and PPH were lacking in 2018, PIH which was available indicated massive increase of 52 cases from the previous year (2017) (Source: TTH Data - 2015, $2016 \&$ 2017). The information, however, gathered may be due to poor preconception knowledge among women.

Notwithstanding, little has been done to examined women's knowledge and health behaviors before and after receipt of targeted preconception education and counseling in Ghana. Besides, the prevalence of the problems associated with ineffective preconception knowledge on the part of the reproductive age woman in the country remains unclear. More so, lack of preconception knowledge is an assumed contributor to several causes of poor pregnancy outcomes most especially in the Northern sector of the country. As Frey and Files (2006) have observed that the concept of preconception care has been articulated for a long time, but unfortunately have not become part of the routine practice especially knowledge and practices on preconception care among reproductive age women. It is in the light of this that this study intended to determine the knowledge level and practice of preconception among reproductive age women in the Tamale Metropolis of Ghana.

\section{METHODOLOGY}

The study employed analytic cross-sectional study design with a quantitative approach. The study was conducted at the Tamale Teaching Hospital in the Tamale Metropolis in the Northern Region of Ghana. A semi-structured questionnaire which has both open-ended and close-ended questions was used for data gathering. Questions on knowledge of preconception were adopted from Southampton Women's Survey (2006).

Puerperal women in the postnatal unit of the Tamale Teaching Hospital, who were yet to be discharged, including referred cases, were selected as target population for this study. The exclusion criteria were women who have never delivered and menopausal women. The sample size was 363 puerperal women.

Purposive sampling method was used to attain the required sample size. The participants were recruited during their early puerperal stage. Data was analyzed using SPSS version 25, and represented by frequencies and percentages. In the analyses, a p-value $<0.05$ was considered statistically significant when variables were cross-tabulated. 


\section{FINDINGS}

\section{Socio-demographic characteristics}

The most represented age category of puerperal women was above 30 years $(44.3 \%)$, followed by the 25 to 30 years group $(40.5 \%)$ and $15.2 \%$ were less than 25 years. The mean age was $30.56 \pm 6.44$ years. More than three fourth $(84.8 \%)$ of the respondents were married and almost $75 \%$ had formal education, but $24.8 \%$ of their partners had no formal education. Almost half (49.6\%) of the respondents were Muslims and $42.1 \%$ of them were Dagombas. Whiles respondents' partners were predominantly public/civil servants $(49.0 \%)$, the data showed $35.5 \%$ women were petty traders. Most of them (66.1\%) also resided in the urban area of the Tamale Metropolis. Table 1 below gives detail of the background of respondents.

Table 1: Socio-demographic characteristics of respondents $(\mathrm{N}=363)$

\begin{tabular}{|c|c|c|}
\hline Background information & $\begin{array}{c}\text { Frequency } \\
(\mathrm{N})\end{array}$ & $\begin{array}{c}\text { Percentage } \\
(\%)\end{array}$ \\
\hline \multicolumn{3}{|l|}{ Age } \\
\hline$<25$ & 55 & 15.2 \\
\hline $25-30$ & 147 & 40.5 \\
\hline$>30$ & 161 & 44.3 \\
\hline Mean \pm standard deviation of age & \multicolumn{2}{|c|}{$30.56 \pm 6.44$} \\
\hline Marital status & & \\
\hline Single & 36 & 9.9 \\
\hline Married & 308 & 84.8 \\
\hline Co-habitating & 18 & 5.0 \\
\hline Divorced & 1 & .3 \\
\hline \multicolumn{3}{|l|}{ Maternal educational status } \\
\hline No formal education & 91 & 25.1 \\
\hline Primary & 32 & 8.8 \\
\hline JHS & 44 & 12.1 \\
\hline SHS/Vocational & 64 & 17.6 \\
\hline Tertiary & 132 & 36.4 \\
\hline \multicolumn{3}{|l|}{ Educational status of partner } \\
\hline No formal education & 90 & 24.8 \\
\hline Primary & 21 & 5.8 \\
\hline JHS & 33 & 9.1 \\
\hline SHS/Vocational & 36 & 9.9 \\
\hline Tertiary & 179 & 49.3 \\
\hline Others (missing due to divorce or death) & 4 & 1.1 \\
\hline \multicolumn{3}{|l|}{ Religion } \\
\hline African Tradition & 21 & 5.8 \\
\hline Islam & 180 & 49.6 \\
\hline Christianity & 162 & 44.6 \\
\hline \multicolumn{3}{|l|}{ Tribe } \\
\hline Dagomba & 153 & 42.1 \\
\hline Gonja & 53 & 14.6 \\
\hline Mamprusi & 33 & 9.1 \\
\hline Akan & 79 & 21.8 \\
\hline Others (Frafra, Ewe, etc.) & 45 & 12.4 \\
\hline
\end{tabular}

Source: Field data, 2019 
Table 1: Socio-demographic characteristics of respondents $(N=363)-$ cont'd

\begin{tabular}{lcc}
\hline \multicolumn{1}{c}{ Background information } & $\begin{array}{c}\text { Frequency } \\
(\mathbf{N})\end{array}$ & $\begin{array}{c}\text { Percentage } \\
(\mathbf{\%})\end{array}$ \\
\hline Occupation of woman & 55 & 15.2 \\
Farming & 129 & 35.5 \\
Petty trading & 135 & 37.2 \\
Public/civil servant & 44 & 12.1 \\
Others (seamstress, charcoal burning etc.) & & \\
Occupation of partner & 91 & 25.1 \\
Farmer & 55 & 15.2 \\
Petty trading & 178 & 49.0 \\
Public/civil servant & 25 & 6.8 \\
Others (drivers, butchers, etc.) & 14 & 3.9 \\
Missing (due to divorce, etc.) & & \\
Residence & 240 & 66.1 \\
Urban & 123 & 33.9 \\
Rural
\end{tabular}

Source: Field data, 2019

\section{Maternal Obstetric History}

When the gestational age at birth was assessed, it was realized that higher percentage (76\%) $(276 / 363)$ of the respondents delivered between 36 to 40 weeks, the post term women were $19.3 \%$ of the respondents, and the preterm group $4.7 \%$.

On maternal obstetrics characteristics, majority of the respondents $(69.7 \%)$ had more than one live birth (multiparous) whiles about $30.3 \%$ were primiparous (single parity). More so, it was found among the 64 women who claimed to have lost a pregnancy, $76.6 \%$ had a single pregnancy lost, $10(15.6 \%)$ had lost two pregnancies, whiles $7.8 \%$ had lost three. Pregnancies that were lost within the first six months after conception represented $87.5 \%$ of the respondents. It was found that all birth outcomes recorded was significantly associated with parity, there was no association between the outcome variables and concurrent loss of pregnancy and number of pregnancies lost except for birth weight $(r=0.202, \mathrm{p}=0.000)$. Table 2 highlights the details of the above information. 
Table 2: Maternal obstetrics characteristics $(\mathrm{N}=363)$

\begin{tabular}{|c|c|c|c|c|c|}
\hline \multirow[t]{2}{*}{ Variables } & \multirow[t]{2}{*}{$\mathbf{N}(\%)$} & \multicolumn{4}{|c|}{ Pregnancy outcomes ( $r, p$-value) } \\
\hline & & PPH & APH & PIH & Birth weight \\
\hline \multicolumn{6}{|l|}{ Parity } \\
\hline Primiparous & $110(30.3 \%)$ & $-0.121, \mathbf{0 . 0 2 1}$ & $0.110, \mathbf{0 . 0 3 7}$ & $-0.125, \mathbf{0 . 0 1 7}$ & $0.202, \mathbf{0 . 0 0 0}$ \\
\hline Multiparous & $253(69.7 \%)$ & & & & \\
\hline \multicolumn{6}{|l|}{$\begin{array}{l}\text { Ever lost } \\
\text { pregnancy }\end{array}$} \\
\hline Yes & $64(17.6 \%)$ & $-0.003,0.953$ & $-0.004,0.937$ & $-0.010,0.846$ & $-0.003,0.953$ \\
\hline No & $299(82.4 \%)$ & & & & \\
\hline $\begin{array}{l}\text { Number of } \\
\text { pregnancies lost }\end{array}$ & $\mathrm{N}=64$ & & & & \\
\hline One & $49(76.6 \%)$ & & & & \\
\hline Two & $10(15.6 \%)$ & $-0.042,0.738$ & $-0.042,0.738$ & $0.116,0.356$ & $0.202, \mathbf{0 . 0 0 0}$ \\
\hline Three & $5(7.8 \%)$ & & & & \\
\hline \multicolumn{6}{|l|}{$\begin{array}{l}\text { Month at which } \\
\text { baby was lost }\end{array}$} \\
\hline At least six months & $56(87.5 \%)$ & & & & \\
\hline $\begin{array}{l}\text { More than six } \\
\text { months }\end{array}$ & $8(12.5 \%)$ & $0.047,0.711$ & $-0.047,0.738$ & $0.116,0.356$ & $-0.024,0.852$ \\
\hline \multicolumn{6}{|l|}{ Mode of delivery } \\
\hline$* * \mathrm{SVD}$ & $288(79.3 \%)$ & $0.037,0.476$ & $0.028,0.590$ & $0.010,0.848$ & $0.004,0.940$ \\
\hline$* * \mathrm{C} / \mathrm{S}$ & $75(20.7 \%)$ & & & & \\
\hline \multicolumn{6}{|c|}{ Source: Field data, 2019} \\
\hline$* *$ Key & & & & & \\
\hline
\end{tabular}




\section{Knowledge of puerperal women on preconception care}

When respondents were asked if they had heard of preconception care, 37.2\% ( $n=135 / 363)$ claimed to have heard about it, whiles majority $228(62.8 \%)$ denied any hearing of preconception care. However, when the respondents were asked to describe preconception care, $77.0 \%$ of the respondents who claimed to have heard of preconception care said it is the preparation and care given to women by health workers before pregnancy. A few (11.9\%) said it is care given to pregnant women and those who stated knowledge of women on conception represented $11.1 \%$.

In view of this the respondents' idea on preconception health was assessed to evaluate their knowledge. Majority of the respondents $(78.2 \%)$ knew it was important to live a healthy life before conception with a 211 of the participants acquiring the information from health workers among other sources. A little more than half of the respondents $(50.7 \%)$ did not know that folic acid and vitamin supplements were significant for a successful pregnancy. This is shown in Table 3.

\section{Table 3: Knowledge on preconception health $(\mathrm{N}=\mathbf{3 6 3})$}

\begin{tabular}{lcc}
\hline \multirow{2}{*}{ Question } & \multicolumn{2}{c}{ Response Rate (N=363) } \\
\cline { 2 - 3 } & Yes (\%) & No (\%) \\
\hline Good health life before conception important for you and the & & \\
baby & $284(78.2 \%)$ & $79(21.8 \%)$ \\
Source of information on the importance of good health before conception & \\
- Health worker & $211(74.3 \%)$ & - \\
- Family/Friend & $21(7.4 \%)$ & - \\
$-\quad$ Radio/TV & $22(7.7 \%)$ & - \\
- School & $27(9.5 \%)$ & - \\
- Pharmacist & $3(1.1 \%)$ & - \\
Folic acid and vitamin supplements were good for conception & $179(49.3 \%)$ & $184(50.7 \%)$ \\
\hline
\end{tabular}

Source: Field data, 2019

Observation from the above data showed that the study's participants tended to have a fair knowledge on preconception care.

However, the correlation between knowledge on the importance of folic acid and vitamin supplements in pregnancy and birth outcomes showed no significant relationship, except PPH which showed a strong correlation $(r=-0.183, \mathrm{p}=0.000)$. This is shown in Table 4. 
Table 4: Bivariate analysis between knowledge on the importance Folic acid and Birth outcomes

\begin{tabular}{|c|c|c|c|}
\hline \multirow[t]{2}{*}{ Variables } & \multicolumn{2}{|c|}{$\begin{array}{l}\text { Knowledge on Folic acid } \\
\text { and Vitamin supplements }\end{array}$} & \multirow[t]{2}{*}{$r, p$-value } \\
\hline & Yes (\%) & No $(\%)$ & \\
\hline \multicolumn{4}{|c|}{ Maternal birth outcome } \\
\hline PPH & $99(27.3 \%)$ & $264(72.7 \%)$ & $-0.183, \mathbf{0 . 0 0 0}$ \\
\hline $\mathrm{APH}$ & $35(9.6 \%)$ & $328(90.4 \%)$ & $0.014,0.793$ \\
\hline $\mathrm{PIH}$ & $100(27.5 \%)$ & $263(72.5 \%)$ & $-0.09,0.086$ \\
\hline Child birth outcome & $\mathbf{N}$ & $(\%)$ & \\
\hline Low birth weight & 48 & 13.2 & \\
\hline Normal birth weight & 302 & 83.2 & $-0.043,0.412$ \\
\hline Macrosomia & 13 & 3.6 & \\
\hline
\end{tabular}

Source: Field data, 2019

\section{Association between preconception care knowledge and birth outcomes}

The study found $27.3 \%$ prevalence of PPH, 9.6\% of APH and $27.5 \% \mathrm{PIH}$ among the puerperal women. Bivariate analysis of correlation between knowledge on preconception care and $\mathrm{PPH}$ showed an inverse relation, implying that as maternal knowledge on preconception care increases, the prevalence of PPH decreases, whiles PPH would decrease among women with high knowledge level on preconception care on the other hand $(r=-0.138, \mathrm{p}=0.008)$. This observation was different in APH women where there was no significant association with preconception care knowledge showed by Pearson $r$ of 0.00 . Similarly, there was no significant relation to the birth weight of neonates, but the association between the independent variable and $\mathrm{PIH}$ was significant showing inverse relation $(r=-0.104, \mathrm{p}=0.047)$. This is shown in Table 5 .

Table 5: Association between preconception care knowledge and birth outcomes

\begin{tabular}{|c|c|c|c|}
\hline \multirow[t]{2}{*}{ Variables } & \multicolumn{2}{|c|}{$\begin{array}{l}\text { Knowledge on preconception } \\
\text { care among women }(\mathrm{N}=363)\end{array}$} & \multirow[t]{2}{*}{$r$, p-value } \\
\hline & Yes (\%) & No $(\%)$ & \\
\hline \multicolumn{4}{|c|}{ Maternal birth outcomes } \\
\hline PPH & $99(27.3 \%)$ & $264(72.7 \%)$ & $-0.138, \mathbf{0 . 0 0 8}$ \\
\hline $\mathrm{APH}$ & $35(9.6 \%)$ & $328(90.4 \%)$ & $0.000,0.995$ \\
\hline $\mathrm{PIH}$ & $100(27.5 \%)$ & $263(72.5 \%)$ & $-0.104, \mathbf{0 . 0 4 7}$ \\
\hline Childbirth outcomes & $\mathbf{N}$ & $(\%)$ & \\
\hline Low birth weight & 48 & 13.2 & \\
\hline Normal birth weight & 302 & 83.2 & $-0.04,0.412$ \\
\hline Macrosomia & 13 & 3.6 & \\
\hline
\end{tabular}

Source: Field data, 2019 


\section{Practices of preconception care}

In terms of practice on preconception care, $73.8 \%$ did not modify their diet before conception, alcoholic beverages consumption before conception was a little higher than smoking among women. More than half of the respondents (51.2\%) were screened for either STIs or genetic disorders before conception, whiles $79.3 \%$ sought for fertility advice. Though $77.4 \%$ haltered the use of contraception before they conceived, surprisingly, $90.6 \%$ continued to use caffeinated products.

When it comes to preparations made before pregnancy, it was detected that out of the 363 respondents, $37.5 \%(n=136 / 363)$ prepare for their pregnancies whiles the $62.5 \%$ made less attempts to prepare for their pregnancies. For those who prepare before conception, $7.4 \%$ sought preconception care services, $38.9 \%$ claimed to purchase their materials or items in wait for the unborn baby and themselves, and $18.4 \%$ took folic acid as a vitamin supplement among other responses. Table 6 shed light on the preconception practices.

Table 6: Preconception practices among pregnant women

\begin{tabular}{lcc}
\hline \multicolumn{1}{c}{ Variables } & \multicolumn{1}{c}{ Response Rate (N=363) } \\
\cline { 2 - 3 } Practices by respondents & & No (\%) \\
\hline Modified diet & $95(26.2 \%)$ & $268(73.8 \%)$ \\
Took steps to change weight & $120(33.1 \%)$ & $243(66.9 \%)$ \\
Consumed alcohol & $12(3.3 \%)$ & $351(96.7 \%)$ \\
Smoking & $9(2.5 \%)$ & $354(97.5 \%)$ \\
Vaccinated against infectious diseases & $148(40.8 \%)$ & $215(59.2 \%)$ \\
Screened for STIs and genetic disorders & $186(51.2 \%)$ & $177(48.8 \%)$ \\
Dental checks & $38(10.5 \%)$ & $325(89.5 \%)$ \\
Used contraceptives & $82(22.6 \%)$ & $281(77.4 \%)$ \\
Sought fertility advice & $75(20.7 \%)$ & $288(79.3 \%)$ \\
Stopped caffeine intake & $34(9.4 \%)$ & $329(90.6 \%)$ \\
\hline Preparations made before conception & $\mathbf{N}(\mathbf{\%})$ & - \\
\hline Financial preparation & $22(16.2 \%)$ & - \\
Folic acid intake & $25(18.4 \%)$ & - \\
Halt contraception & $6(4.4 \%)$ & - \\
Healthy diet intake & $11(8.1 \%)$ & - \\
Purchase items & $53(38.9 \%)$ & - \\
Medical checkups & $7(5.1 \%)$ & - \\
Moderate activities & $2(1.5 \%)$ & \\
Seek for preconception care & $10(7.4 \%)$ & - \\
Total & $\mathbf{1 3 6}(\mathbf{1 0 0 \%})$ & \\
\hline Source: Fid & & - \\
\hline
\end{tabular}

Source: Field data, 2019

Critically looking at the data above on the practices on preconception by the respondents of this study, majority gave negative responses pointing to the fact that their answers were wrong as against the few who replied in the affirmative. However, 53 (38.9\%) out of the 136 respondents 
purchased household items as a means of preparing towards conception with few $(5.1 \%)$ having medical checkups and preparing financially (16.2\%) before conception. Consequently, these assertions pointed to the fact that participants for this study had poor practices of preconception care.

When the participants' preparedness for conception was cross-tabulated against maternal and child birth outcomes respectively, the findings had no statistical association among the variables. This is shown in Table 7 below.

Table 7: Association between preparations made before pregnancy and birth outcomes

\begin{tabular}{|c|c|c|c|}
\hline \multirow{3}{*}{ Birth Outcomes } & \multirow{2}{*}{\multicolumn{2}{|c|}{$\begin{array}{c}\text { Response Rate }(\mathbf{N}=\mathbf{3 6 3}) \\
\begin{array}{c}\text { Preparedness for } \\
\text { conception }\end{array}\end{array}$}} & \multirow{3}{*}{$\begin{array}{r}\text { Test-statistic } \\
r, p \text {-value } \\
\end{array}$} \\
\hline & & & \\
\hline & Yes & No & \\
\hline \multicolumn{4}{|c|}{ Maternal birth outcomes } \\
\hline $\mathrm{PPH}$ & $99(27.3 \%)$ & $264(72.7 \%)$ & $-0.078,0.139$ \\
\hline APH & $35(9.6 \%)$ & $328(90.4 \%)$ & $-0.060,0.254$ \\
\hline PIH & $100(27.5 \%)$ & $263(72.5 \%)$ & $-0.095,0.070$ \\
\hline Childbirth outcome & $\mathbf{N}$ & $\%$ & \\
\hline Low birth weight & 48 & 13.2 & $-0.044,0.398$ \\
\hline Normal birth weight & 302 & 83.2 & \\
\hline Macrosomia & 13 & 3.6 & \\
\hline
\end{tabular}

\section{DISCUSSION}

The study assessed the preconception knowledge and practices among women in fertility age in the Tamale Teaching Hospital of Ghana.

When participants of the study were asked if they had heard of preconception care as part of evaluating their knowledge, 37.2\% ( $\mathrm{n}=135 / 363)$ claimed to have heard about it, whilst majority $228(62.8 \%, n=363)$ denied any hearing of preconception care. This report was in agreement with Al-Akour and colleague's (2015) study that indicated 50\% of their participants showed awareness of preconception care among women and men. More so, 74.3\% ( $n=211 / 263)$ of this research had their information on the importance of good health before conception from the health worker; contrary to this view, only $34 \%$ of all women reported acquiring no information about preconception health behaviours (Stephenson et al., 2014). Mittal and colleagues (2014) said knowledge about preconception care and its effects on a potential pregnancy manifests large impact. Gunaratna and colleagues (2015) reported that lack of knowledge about common preconception care seems to be one of the critical factors hindering widespread application of the practice and consequently having negative impacts $(\mathrm{p}<0.001)$. However, $78.2 \%$ of the participants of this study knew it was important to live a healthy life before conception.

In terms of description of preconception care, $77.0 \%$ of this study respondents said it is the preparation and care given to women by health workers before pregnancy. A few (11.9\%) described it as care given to pregnant women. This implied that some of the respondents were of 
the view that preconception care is the same as antenatal care. It was, therefore, explained in another study that preconception care was interventions characterized by the need to start and sometimes complete a designated intervention before conception occurs (Seshadri et al., 2012). In conclusion, preconception care is the provision of biomedical, behavioural and social health interventions to women and couples before conception occurs aiming at improving their health status, and reducing behaviours and individual and environmental factors that contribute to poor maternal and child health outcomes. Its ultimate aim, therefore, is to improve maternal and child health, in both the short and long term (WHO, 2013).

As part of the practices made towards preconception care, women are to make preparations prior to conception. Among this study's participants, 39\% of them purchased household items for the baby and themselves, whilst $18.4 \%$ took folic acid and other vitamin supplements, $16.4 \%$ made financial preparations towards their conception, and $7.4 \%$ sought preconception care. These findings were in agreement by a comment that suggested that resources may be used to improve reproductive health of women, men and couples in order to optimize health and knowledge before conceiving a pregnancy (Ojukwu et al., 2016). However, the idea of practicing preconception care has not been a concept acknowledged among most reproductive age women (Frey \& Files, 2006).

\section{CONCLUSION}

Women in fertility age attending the Tamale Teaching Hospital in the Northern Region of Ghana tended to have a fair knowledge and poor practices on preconception care.

\section{RECOMMENDATIONS}

1. At the community level the study recommended to the Ghana Health Service (GHS) that a mother-to-mother support group be formed among women in their reproductive age and this could help encourage one another to discuss about their health before pregnancy and share success stories on birth outcomes and report to the facility in case of any problems.

2. The knowledge gap of preconception care in this part of the country requires the Ministry of Health, and the GHS in particular, to put in place at the various health delivery levels, including encouraging women in their reproductive age to seek information about their health and impending pregnancy.

3. Preconception care needs to be integrated into other social services, such as the adolescent reproductive health services, and/or social franchises for easy accessibility to practice but not only assigning to healthcare providers as their duty at the health post.

4. Women and children protecting agencies, such as the Ministry of Gender, Children and Social Protection in collaboration with the GHS, should publish more information on the need to seek preconception care before conception. 


\section{REFERENCES}

Al-Akour, N., Sou'Ub, R., Mohammad, K., \& Zayed, F. (2015). Awareness of preconception care among women and men: A study from Jordan. Journal of Obstetrics and Gynaecology, 35(3), 246-250.

Chuang, C. H., Velott, D. L., \& Weisman, C. S. (2010). Exploring knowledge and attitudes related to pregnancy and preconception health in women with chronic medical conditions. Maternal and Child Health journal, 14(5), 713-719. https://doi.org/10.1007/s10995-009-0518-6

Frey, K. A., \& Files, J. A. (2006). Preconception healthcare: What women know and believe. Maternal and Child Health Journal, 10(1), 73-77.

Gunaratna, N. S., Masanja, H., Mrema, S., Levira, F., Spiegelman, D., Hertzmark, E.,..., \& Fawzi, W. (2015). Multivitamin and iron supplementation to prevent periconceptional anemia in rural tanzanian women: A randomized, controlled trial. PLoS One, 10(4), e0121552-e0121552. doi:10.1371/journal.pone.0121552.

Harelick, L., Viola, D., \& Tahara, D. (2011). Preconception health of low socioeconomic status women: Assessing knowledge and behaviors. Women's Health Issues, 21(4), 272-6. doi:10.1016/j.whi.2011.03.006.

Harelick, L., Viola, D., \& Tahara, D. (2011). Preconception health of low socioeconomic status women: Assessing knowledge and behaviors. Women's Health Issues, 21(4), 272-276.

Kinney, M. V., Kerber, K. J., Black, R. E., Cohen, B., Nkrumah, F., Coovadia, H., . ., \& Lawn, J. E. (2010). Sub-Saharan Africa's mothers, newborns, and children: Where and why do they die? PLoS medicine, 7(6), e1000294. https://doi.org/10.1371/journal.pmed.1000294.

Lassi, Z. S., Dean, S. V., Mallick, D., \& Bhutta, Z. A. (2014). Preconception care: Delivery strategies and packages for care. Reproductive Health, 11(Suppl. 3), S7. doi:10.1186/1742-4755-11-S3-S7.

Mitchell, E. W., Levis, D. M., \& Prue, C. E. (2012). Preconception health: Awareness, planning, and communication among a sample of US men and women. Maternal and Child Health Journal, 16(1), 31-39. doi:10.1007/s10995-010-0663-y.

Mittal, P., Dandekar, A., \& Hessler, D. (2014). Use of a modified reproductive life plan to improve awareness of preconception health in women with chronic disease. The Permanente Journal, 18(2), 28.

Ojukwu, O., Patel, D., Stephenson, J., Howden, B., \& Shawe, J. (2016). General practitioners' knowledge, attitudes and views of providing preconception care: A qualitative investigation. Upsala Journal of Medical Sciences, 121(4), 1-8. doi:10.1080/03009734.2016.1215853.

Seshadri, O. P., Nelson-Piercy, C., \& Chappell, L. C. (2012). Prepregnancy care. BMJ, 344(3467). 
Singh, S., Sedgh, G., \& Hussain, R. (2010). Unintended pregnancy: Worldwide levels, trends, and outcomes. Studies in Family Planning, 41(4), 241-250.

Stephenson, J., Patel, D., Barret, G., Howden, B., Ojukwu, O., Pandya, P., \& Shawe, J. (2014). How do women prepare for pregnancy? Precocneption experiences of women attending antenatal services and views of health professionals. PLoS One, 9(7): e103085. doi:10.1371/journal.pone.0103085

Southampton Women's Survey, 2006. Available at https://www.mrc.soton.ac.uk/sws/

UNICEF. (2010). Levels and Trends in Child Mortality: Report 2010: Estimates Developed by the UN Inter-Agency Group for Child Mortality Estimation. United Nations Children's Fund.

WHO (2013). Meeting to develop a global consensus on preconception care to reduce maternal and childhood mortality and morbidity: 6-7 February 2012 meeting report. Geneva: World Health Organization Headquarters. 